\title{
The ripple of fear, sympathy and solidarity during the Boston bombings
}

\author{
Yu-Ru Lin ${ }^{1 *}$ and Drew Margolin²
}

"Correspondence: yurulin@pitt.edu 'School of Information Sciences, University of Pittsburgh, Pittsburgh, PA 15260, USA

Full list of author information is available at the end of the article

\begin{abstract}
The Boston Marathon bombing presents a rare opportunity to study how a disruptive event can trigger inter-communal emotions and expressions - where members of one community express feelings about and support for members of a distant community. In this work, we use over 180 million geocoded tweets over an entire month to study how Twitter users from different cities expressed three different emotions: fear, sympathy and solidarity, in reaction to the bombings. We capture spikes in fear in different cities by using sentiment and time-series analyses, and track expressions of sympathy and solidarity based on the emergent use of two hashtags, \#prayforboston and \#bostonstrong, widely adopted after the bombings. We find first that the extent to which communities outside Boston express these emotions is correlated with their geographic proximity, social network connections, and residents' direct, physical experiences with Boston (captured by the number of citizens who had visited Boston recently). This general effect shows interesting differences across the different kinds of emotions, however. Analyses show that the extent to which residents of a city visit Boston is the best predictor of fear and solidarity expression, as well as a strong predictor of the expression of sympathy. The expression of fear is also directly related to the expression of solidarity. Our study has theoretical implications regarding the diffusion of information and emotional contagion as well as practical implications for understanding how important information and social support can be effectively collected and distributed to populations in need.
\end{abstract}

Keywords: emotional contagion; disaster; crisis management; social support; natural experiment; social network analysis; social media; communication streams

\section{Introduction}

The goal of terrorism is to spread fear. Through the perpetration of spectacular violence, terrorists can induce irrational decisions in frightened populations, weakening their infrastructure and public confidence [1] and, in some cases, persuading the population to give in to terrorist demands [2]. Understanding how fear spreads through a population is thus critical to efforts to limit the damage and impact of terrorist acts.

The dynamics of fear are difficult to characterize, however, as they involve complex processes that operate at multiple levels. Individuals become afraid when they perceive a threat over which they believe they have little control $[3,4]$. These perceptions are formed by appraising stimuli from their physical environment but also from social cues and context [5,6] provided through inter-personal conversations [5], mass media [7], and more recently, social media [8]. In addition to being induced by perceptions of risk at the indi-

\section{Springer}

(c) 2014 Lin and Margolin; licensee Springer. This is an Open Access article distributed under the terms of the Creative Commons Attribution License (http://creativecommons.org/licenses/by/4.0), which permits unrestricted use, distribution, and reproduction in any medium, provided the original work is properly credited. 
vidual level, fear can be passed along through emotional contagion across social network ties $[9,10]$. Group processes also participate in the spread of fear. When individuals identify themselves with a social group, they are likely to feel threatened when this group is threatened, even if they themselves are not in immediate danger [11].

Further complicating matters is the fact that individuals may not experience fear in a stable, observable manner. This makes fear difficult to measure. Fear motivates individuals to adjust their decisions and behavior, generally toward an avoidance of further risk [3], including preferences for government policies and demands for government response [12]. When avoidance or other coping strategies are successful, fear dissipates [13, 14]. When coping strategies are unsuccessful or are insufficient to reduce threat, fear can remain over very long periods of time [14]. However, when individuals become aware of strategies that can address the threat and these strategies are delayed, ignored, or obstructed, fear often converts to anger [13]. This potential for fear to rise quickly, influence decision-making, and then disappear or transform into other emotions makes it difficult to measure in realworld situations.

Thus the question of 'who is likely to be afraid' in the immediate aftermath of a terrorist attack is important and yet difficult to answer. Of particular interest is the spread of fear to populations outside of the city or community directly under attack. After the terrorist attacks of September 11,2001, researchers documented the broad diffusion of fear and fear related responses, such as post-traumatic stress disorder, to cities outside of New York and countries outside of the US [15-17]. These findings suggest that various social connections between communities serve as channels over which emotional responses to terrorism are amplified [5].

This paper represents a first systematic examination of such community-community ties. Using the attack at the Boston Marathon as a focal event, we ask which other major US and world cities demonstrated the greatest emotional consistency with Bostonians after the attack by analyzing tweets from these cities in terms of their expressions of fear, sympathy, and social solidarity. We then design a prediction framework that predicts these post-event community responses based on the pre-event Twitter communication streams.

We find that several factors are associated with sharing fear with the community targeted by a terrorist act. Cities that are geographically closer, where individuals share more social media relationships with Boston residents, and where individuals have more immediate, direct experience with Boston, were more likely to share fear with Bostonians. Direct experience, however, shows the strongest and most robust relationship to fear. We also examine the role that these three factors play in the expression of social support for Boston in terms of expressions of sympathy and solidarity. While expressions of sympathy are predicted by the same factors as fear, expressions of solidarity, evidenced by the use of the defiant \#bostonstrong hashtag, reveal interesting dynamics in which fear itself appears to play an important role.

Through the analysis of community-wide expressions of fear, sympathy, and solidarity in reaction to the Boston bombings, this study makes the following contributions:

(1) Identifies robust community-to-community emotional relationships via social media;

(2) Discerns a key antecedent to these relationships: direct, personal experience being a dominant predictor; 
(3) Provides a quantitative understanding of the emotional impact of a terrorist act on its target audiences.

\section{Motivation and background}

\subsection{Background}

The bombing of the Boston Marathon on April 15, 2013 resulted in 3 deaths and more than 250 casualties. Over the subsequent week police engaged in an area-wide manhunt that resulted in a 'lockdown' of Boston and neighboring suburbs [18-20]. Citizens of Boston, who were at one point instructed directly by the Governor of Massachusetts to stay in their homes to avoid danger, were understandably afraid. Examples were seen on Twitter: 'Just can't shake the horror of yesterday. A search warrant has been executed in a Revere apt complex, even closer to home.' 'Holy shit first the bombing now a shooting at MIT can't people just leave Boston alone.' Bostonians were not the only ones who became afraid, however. Those with loved ones who lived in Boston, or had traveled to Boston for the marathon, worried for their safety, e.g., 'Thinking of all my family and people I know in Massachusetts/Boston area and imagining their fear is heartbreaking. For others, their sense of the benevolence of the world was shaken [7], e.g., 'This world is becoming a truly scary place. As though bombing a marathon wasnt enough.' 'Seriously what the hell is going on in this city... \#peoplesuck \#gunshots \# explosions \#getoutofhere \#bostonstrong.' Fear was not the only response in Boston, however, or in its fellow communities. The slogan 'Boston Strong' emerged as a rallying cry to demonstrate the city's defiance in response to the terrorists' attempt to intimidate them [21]. Boston-area residents organized community events such as the 'Run to Remember' memorial foot-race and music concerts. Just as the attacks spread fear well beyond Boston itself, expressions of social support were also directed to Boston from around the globe. In New York, fans of the New York Yankees baseball team, the bitter rival of Boston's team (the Red Sox), stood in their stadium to sing 'Sweet Caroline,' the Red Sox anthem [22]. In Chicago, more than 200 runners gathered for a run of solidarity [23]. A week after the Boston Marathon, thousands of marathon runners in London wore a black ribbon in solidarity with the people of Boston [24].

Interestingly, such extensions of support across community-community relations have been observed in other circumstances when tragic or disastrous events befall a particular locale [25]. What do these reactions reveal about the nature of social organization in the 21st century? Recent technical and social innovations have enabled individuals to break out from their traditional geographic and cultural boundaries, creating a 'network society' [26]. This de-coupling of the social from the geographic has given individuals increased personal autonomy but has also created challenges for civic institutions concerned with supporting their needs and anticipating their behavior [27, 28]. Does London have a particular kind of social tie to Boston? If so, what is its basis? Are these ties based on interpersonal relationships, or on the basis of shared identification with some set of cultural symbols, such as the rituals around baseball that appear to have motivated the responses of Yankee fans $[29,30]$. What motivates these inter-communal relationships? What characteristics of the relationships between communities might lead one to respond when the other is attacked or befallen by disaster, and how do these inter-communal relationships influence the impact and effectiveness of terrorist acts in promoting fear? 


\subsection{Ripples of fear and related emotions}

According to legal scholar Cass Sunstein [1] 'Terrorists show a working knowledge of' the dynamics of fear, in particular, the kinds of spectacles that prompt the general public to become afraid. Experts typically evaluate threats, such as those posed by terrorist attacks, in terms of expected costs and casualties derived from the probability of an attack and its typical consequences [5]. By contrast, the public's responses to threats are subject to what risk researchers call social amplification [5, 31]. In social amplification, individuals heighten their emotion and communication about some threats and attenuate their responses to others in a manner that is inconsistent with expert calculations of their expected outcomes. Threats are socially amplified because individuals appraise and interpret them in the context of personal circumstances, social relationships, and institutional expectations that include factors that go beyond the calculable, physical consequences constituted by the threats themselves. Such contexts include, for example, concerns about the quality of the information they are receiving or worries that their government is not competently addressing the problem [6].

Terrorist attacks are designed to be amplified in this way [32]. First, the vivid and spectacular nature of terrorist violence draws increased attention and intense emotion $[6,33]$. The irrevocable and horrifying nature of the terrorist outcomes also invokes dread $[6,31,33,34]$, a powerful feature in the evaluation of risk. When individuals dread an outcome, they are more likely to take action and to demand that others take action. They become insensitive to rational appeals and trade-offs as fear motivates them to insist the outcome be avoided at almost any cost $[1,31]$. Second, the unexpected nature of the attack also serves what researchers refer to as a signalling function. An event has high signalling value when its occurrence suggests that previously unconsidered risks deserve greater attention and that existing institutions and authorities are not adequately prepared to deal with a threat $[6,34]$. In this way, terrorism undermines the public's confidence in its own government and institutions [35,36]. Furthermore, the fearful individuals are likely to over-estimate the likelihood of future terrorist events [3, 12,33].

A third feature of terrorist acts is their relationship to groups and group identities. Selfcategorization refers to the cognitive processes that lead people to identify with particular groups, such as ethnic, regional, or national communities [11, 29]. Social identity refers to the evaluations individuals make of themselves and others based on their group membership [29]. Disasters tend to impact the ways in which people self-categorize themselves. Individuals normally participate and identify with many distinct (but somewhat overlapping) communities [29]. When one such group is threatened, however, this identity becomes more salient and many individuals will more closely identify with it [37]. The effect is to increase solidarity within the 'in-group,' with individuals becoming more charitable and supportive of those who they recognize sharing their identity [38], while simultaneously becoming more mistrustful of and hostile toward those they perceive to be 'outsiders' [37]. These effects are particularly important in the context of terrorist attacks. Unlike natural disasters, terrorist attacks are socio-political acts directed by members of one group against another. Thus, in addition to signalling that members of one's group are exposed to a previously unanticipated risk, terrorist attacks indicate that these risks are due to the planned, intentional behavior of an out-group [13, 39]. For example, after the attacks of $9 / 11$, Americans all over the country responded by prominently displaying 
American flags [16]. At the same time, many Americans felt more hostile toward Muslim nations and violence against Muslims increased [12].

All of these non-objective, social factors lead the amplification of fear and related emotions in response to terrorist attacks to 'ripple' out from the geographic locale in which the attack takes place. Risk researchers define 'ripple' effects as the effect of an event on emotions, appraisals and decisions in geographically and temporally distant contexts. Ripples can travel over many paths. Vivid images are likely to be carried and shared through media [40], bringing information about the attack to a larger and geographically dispersed audience. At the same time, the 'signal' that existing understandings and institutions have not properly assessed risk and threats leads to the broader conclusion that no one is safe anywhere [41, 42]. Group identification also has a potentially large geographic reach. In a conflict between groups, individuals may feel compelled to choose sides or risk being identified as members of the out-group by both communities [29]. For example, after the 9/11 attacks almost half of Germans surveyed say they agreed with the statement 'we are all Americans now.

In addition to these ripples motivated by identifiable processes, there is also evidence that expressions of emotion are themselves contagious. For example, [9] found that rainfall in one location slightly depresses both residents of that geographic area and their friends at distant locations. Kramer et al. [10] find similar results using a controlled experiment. These findings suggest that the mere incidence of an emotion, such as fear, at a distant location may encourage others to take on that emotion, even if they do not identify with the group that is attacked or believe that the attack is a signal of a new threat.

These ripple effects, and ripples of fear in particular, have important practical consequences for first responders and other civic authorities who must respond to terrorist attacks. Fear can lead to costly and irrational decision-making, including the undertaking of behaviors with greater objective risk [1,43]. For example, after the attacks of 9/11, many individuals substituted driving for flying in planes, actually increasing personal and public risk [1]. The inability to address fears through concrete action can also lead to its persistence over time, a condition associated with post-traumatic stress disorder (PTSD) [7, 34, 44]. Fear can also place demands on local infrastructure, such as the need for increased law enforcement or the perception that local or national governments are not competent or addressing the needs of the people [36], and can even influence long term assessments of the economy [45]. Fear can lead individuals to lean on unfair, irrational biases that unfairly target others for harm [46]. In particular, when individuals perceive that the threatening situation has been brought under control, fear is likely to convert to anger which then motivates attacks against outsiders or others perceived to be a source of threat $[13,36]$.

The connection that people feel to those who were attacked can also spur positive emotions and actions. There is evidence that an individual's emotional proximity to a tragedy is associated with their willingness to extend social support to those in need [47], and that when individuals self-categorize as a members of the threatened community they perceive it as something that effects 'us' rather than a set of others who are distinct from 'me' [48]. For example, after a shooting at Northern Illinois University in February, 2008 students from Virginia Tech University, where there had been a shooting only 10 months before, offered extensive support to their newly victimized 'neighbors' [25]. It is thus possible that fear and support are linked. Those who feel a close connection with the distant, effected 
community will likely feel the threat more acutely and personally, making them both more afraid and yet more willing to help.

The preceding argument suggests there is substantial theoretical and practical value in understanding where ripples of fear and related emotions are likely to flow. When a community in one geographic location is directly attacked, where else do people become afraid? Such information would be useful to civic authorities seeking to anticipate how their local communities might be effected by distant events. It would also shed theoretical light on the social processes most prominent in the diffusion of fear and other responses as well as new insights into how they operate.

To date, however, little research has focused on these emotion spreading processes in response to real-world terrorist attacks or disaster events more broadly. Most studies of emotional responses to terrorist attacks focus on those in the area directly effected. When individuals from other communities are included in the analysis they are used for the purposes of comparison and control $[36,44,49]$ or are treated as a single group characterized as a whole $[7,15,17]$. Conversely, studies of emotional contagion and other forms of diffusion tend to focus on the way that individualized emotions and information about personal events are communicated over social network ties $[9,10,50]$. Thus, these studies provide little insight into how fear or other feelings diffuse when relevant information and emotion is simultaneously broadcast both over social ties and through other channels, such as mass media [51, 52].

Perhaps one of the reasons for limited study in this area is the difficulty of observing geographically dispersed behavior in the immediate aftermath of a terrorist attack. However, social media data offer the potential to overcome this limitation.

\subsection{Social media and collective responses to disasters}

Social media data have been gaining increasing attention in studies of emergencies and disasters, a field often referred to as crisis informatics [53]. Social media data are useful because they contain fine-grained information regarding the timing and location of individual responses. This permits researchers to analyze real-world behaviors in close proximity to dangerous and disastrous events without them having to anticipate where and when they will occur.

Individuals often rely on social media in emergency circumstances to support a variety of information needs that are not fully served by authorities or established news outlets. Social media facilitate 'backchannel communication' [8] by allowing users to obtain timely and accurate information tailored to their local context $[8,53-63]$. In addition to providing information about the threatening event itself, social media can also help coordinate efforts to provide assistance [64, 65].

Consistent with findings from studies of more general behavior, research indicates that individuals who are in areas directly under threat use social media differently than those who are more distant. In particular, directly affected individuals are significantly more likely to share specific, locally relevant information, whereas more distant individuals are more likely to share generic information, such as an image from the disaster [40]. This intensity of information sharing on social media, particularly among locals, has become useful for detecting events or circumstances before they reach mainstream media. Twitter has been utilized as an early detection system for emerging public health problems [6668], real-time emergency detection [69-71] and crisis management [65, 72, 73]. 
The focus of these analyses has largely been on gathering information about the physical realities that correspond to the threat, however, rather than the perceptions and emotions that result from it. Thus, researchers have placed emphasis on the spread of rumor and misinformation with the aim of identifying and removing inaccuracies [65, 74-76]. Less attention has been paid to the diffusion of emotions and social realities, such as group identification, that also follow from the social amplification of threats. One exception is [77], who map the expression of positive and negative emotion in response to Hurricane Sandy. Their findings focus on the unique features of those directly effected by the storm, who are more likely to tweet negative sentiments, rather than on a comparison between the unaffected areas.

Such comparisons are the focus of our work, which advances a systematic understanding of the inter-communal relationships that facilitate ripples of emotion by comparing tweets issued from different cities in response to the Boston Marathon bombings to other observable relationships between these cities and Boston. We employ a concept-based affective lexicon SentiSense [78] to extract different categories of sentiments (e.g., anger, fear, joy, etc.) from the tweets. We then compare these sentiments to three pre-existing ties between each city and Boston: geographic distance, person-to-person relationships, and personal visits between cities. Although other approaches such as LIWC Dictionary or more recent sentiment detection techniques $[79,80]$ are also applicable, SentiSense allows us to efficiently detect multiple emotional categories grounded in psychological theories with broad vocabulary coverage. Using this approach, the scope of our analysis is limited to content written in English. Nevertheless, through the temporal analysis of changes in the sentiment experession captured by a broad set of lexicons, our goal is to develop a systematic understanding regarding how users' expression of fear varied in response to the Marathon bombings. By analyzing the responses of communities outside of Boston to an attack on Boston we ask:

- Which communities, outside of Boston, shared fear with Boston in the wake of the bombings?

- What factors - geographic, social, or experiential - best explain these different levels of community fear?

- Are these same factors associated with expressions of social support?

- How is fear itself associated with expressions of social support?

We discuss our method and results in the following sections.

\section{Method}

In this section, we first describe the data collection and the dataset used in this study. We then present how the variables of interest, including shared fear and social support, were captured in our study. Finally, we describe the key factors for explaining the differences in communities' shared fear and social support and the prediction models that were used to examine the influence of these factors.

\subsection{Data description}

This study used nearly all geotagged tweets collected from the Twitter Streaming API [81]. Figure 1 shows the total number of geocoded tweets (volume) per day over the month of April in the dataset. Tweets without geocodes (latitude and longitude) are removed. The vertical dashed lines indicate the day of Boston bombings (April 15; black line) and the day 


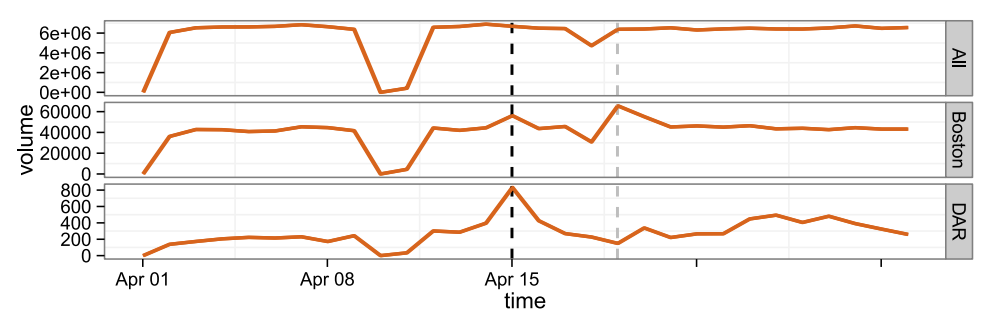

Figure 1 Daily number of geocoded tweets (volume) in dataset. Tweets without geocodes are removed. From top to bottom: the total daily volume, the daily volume within the Boston area, and the daily volume within the direct affected region (DAR). The vertical dashed lines indicate the day of Boston bombings (April 15; black line) and the day of manhunt (April 19; gray line). The tweets posted on April 1, 10 and one half of the day on April 11 were missing due to data collection process errors. There are over 180 million geocoded tweets over an entire month and only tweets posted within the geographical borders of the cities (over 38 million tweets in total) are used in further analysis.

\section{Table 1 List of cities in our study}

US cities: Albuquerque, Anaheim, Arlington, Atlanta, Aurora, Austin, Bakersfield, Baltimore, Boston, Charlotte, Chicago, Cleveland, Colorado Springs, Columbus, Corpus Christi, Dallas, Denver, Detroit, El Paso, Fort Worth, Fresno, Honolulu, Houston, Indianapolis, Jacksonville, Kansas City, Las Vegas, Long Beach, Los Angeles, Louisville, Memphis, Mesa, Miami, Milwaukee, Minneapolis, Nashville, New Orleans, New York, Oakland, Oklahoma City, Omaha, Philadelphia, Phoenix, Portland, Raleigh, Riverside, Sacramento, San Antonio, San Diego, San Francisco, San Jose, Santa Ana Seattle, St. Louis, Tampa, Tucson, Tulsa, Virginia Beach, Washington, Wichita.

Non-US cities: Bangkok, Beijing, Berlin, Bogota, Buenos Aires, Cairo, Delhi, Dhaka, Hanoi, Ho Chi Minh City, Hong Kong, Istanbul, Jakarta, Kuala Lumpur, Lagos, Lima, London, Madrid, Manila, Melbourne, Mexico City, Milan, Montreal, Moscow, Mumbai, Paris, Rio de Janeiro, Santiago, Sao Paulo, Seoul, Shanghai, Singapore, Taipei City, Tokyo, Toronto.

of manhunt (April 19; gray line). Due to data collection process errors, tweets posted on April 1, 10 and half of the day on April 11 were missing. In the following analysis, volumes in the three missing days are excluded when reporting aggregated statistics. The total volume before, during and after the bombing day are $6.59 \mathrm{M}$ tweets/day on average, $6.69 \mathrm{M}$ tweets/day, and 6.36M tweets/day on average. Within the Boston area, the volume before, during and after the bombing day are 42,370 tweets/day on average, 56,131 tweets/day, and 45,668 tweets/day on average.

Following news reports [18], we manually identified the location that covers the area of the two blasts. We categorize tweets from this area as coming from those directly affected by the attacks, and refer to this approximately $0.55 \mathrm{~km}^{2}$ area as the directly affected region' or 'DAR.' Within DAR, the volume before, during and after the bombing day are 234 tweets/day on average, 832 tweets/day, and 331 tweets/day on average.

Cities. In this study, we selected the largest 60 cities in US by metro population based on the US 2010 census. We extended the selection by including the largest cities of the world (also in terms of metro population), yielding an additional 35 (non-US) cities. The list of cities is provided in Table 1.

The criteria for selecting the list of cities was based on the fact that more than half of the world's population lives in urban areas (towns and cities) [82], and $80.7 \%$ of the US population lived in urban areas as of the 2010 Census [83]. We selected cities (or metropolitan areas) with populations of 5 million or more. This selection of world's largest cities covers more than $20 \%$ of the world's urban population (approximately 752.2 millions out of 3.4 billions) [82]. The selection for US cities was similar. We selected cities within the 
US with population over 300,000 , which covers more than $20 \%$ of US urban population (approximately 52.8 millions out of 249.2 millions) [83]. We merged the two lists (several most populated US cities are cross-listed in the set of word's largest cities). We further removed cities for which we did not have Twitter data for the period studied; for example, several populated cities in China such as Guangzhou and Shenzhen were not included in our sample due to the lack of Twitter data resulting from the country's policy of Internet censorship. In total, the selection criteria resulted in 60 US cities and 35 non-US cities.

We used Yahoo Geo API ${ }^{a}$ to query the cities' bounding box information as their approximate geographical borders. In our study, we used all tweets posted within the geographical borders of the cities which yielded $38.78 \mathrm{M}$ tweets in total. Within cities, the total volume before, during and after the bombing day are 1,071,991 tweets/day on average, 1,456,648 tweets/day, and 1,411,842 tweets/day on average.

\subsection{Detecting fear}

To study users' expression of fear, we applied sentiment analysis to extract different sentiments from the text in users' tweet messages. We used a concept-based affective lexicon SentiSense [78] to extract two different kinds of sentiments, fear and joy. As discussed earlier, compared with other approaches $[79,80]$, SentiSense has a broader vocabulary coverage that allows us to efficiently detect multiple emotional categories grounded in psychological theories [78]. Although we were mainly interested in capturing changes in fear expression from the tweet text, it is important to understand whether the changes reflect meaningful changes in sentiments, or just reflect changes in the tweet volumes. For this reason, a different sentiment, joy, was extracted to compare changes of the fear expression at the same time. Examples of fear related keywords include 'fearful', 'unkind', 'craziness', 'crime', 'shudder', 'suffocate', 'dreadfully', 'terror', 'fatal', 'crash', 'anxiously, 'erupt', etc. and joy related keywords include 'satisfied, 'cheerful, 'comfortableness', 'cruise', 'pleased,' 'happiness', 'joyful, 'belonging,' 'exult,' 'rejoicing,' 'eagerly', 'fortunate', etc.

We computed the relative strength of a sentiment within a region as follows. Let $L$ be the list of all words in the sentiment lexicon ( $L$ contains all words related to the 14 different sentiments defined in the SentiSense lexicon), and $L_{\text {fear }}$ and $L_{j o y}$ be the lists of fear- and joy-related words, respectively. The degree of a sentiment type of interest $c \in\{$ fear,joy $\}$ in a tweet $i$, denoted as $s_{i, c}$, is given by

$$
s_{i, c}= \begin{cases}\left|W_{i} \cap L_{c}\right| /\left|W_{i} \cap L\right| & \text { if }\left|W_{i} \cap L\right|>0, \\ 0 & \text { if }\left|W_{i} \cap L\right|=0,\end{cases}
$$

where $W_{i}$ is the words in the text content of tweet $i$. The sentiment index $S_{R T, c}$ of a region $R$ (defined by a bounding box) within a particular time interval $T$ is given by

$$
S_{R T, c}=\frac{1}{m} \sum_{t_{i} \in T, g_{i} \in R} \frac{s_{i, c}}{\sum_{c^{\prime}} s_{i, c^{\prime}}+\epsilon}
$$

where $t_{i}$ and $g_{i}$ are the timestamp and geocode of tweet $i$, respectively, and $m=\mid i: t_{i} \in$ $T, g_{i} \in R \mid . s_{i, c} \in[0,1]$ is the degree of fear or joy in a tweet, and tweets with $s_{i, c}=0$ were still included in this computation. If a tweet does not contain fear or joy sentiment, this will lead to a division-by-zero issue. Therefore we adjusted the denominator by adding a 
(a)DAR

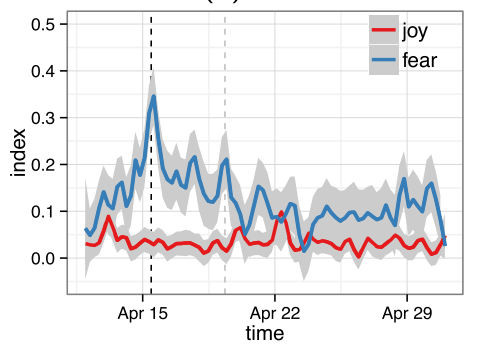

(b)Boston

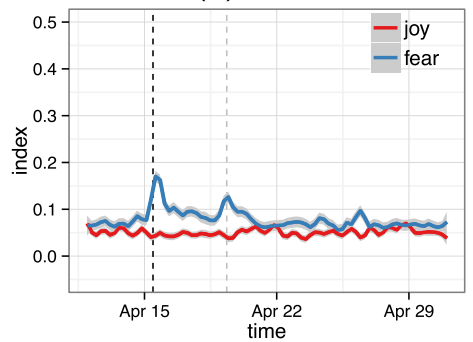

Figure 2 Sentiment indices over time in (a) the direct affected region (DAR) and (b) the City of Boston. The hourly sentiment indices of fear (and joy) before, during and after the Boston bombings are shown in smooth fitted curves over time (in UTC) with shaded area indicating a 95\% confidence region. The vertical dashed lines around April 15 and 19 indicate the times of bombings and manhunt, respectively. The spikes in the level of fear correspond to the Boston bombings and the subsequent events, while the level of joy does not exhibit a sudden increase and is relatively stable over the period.

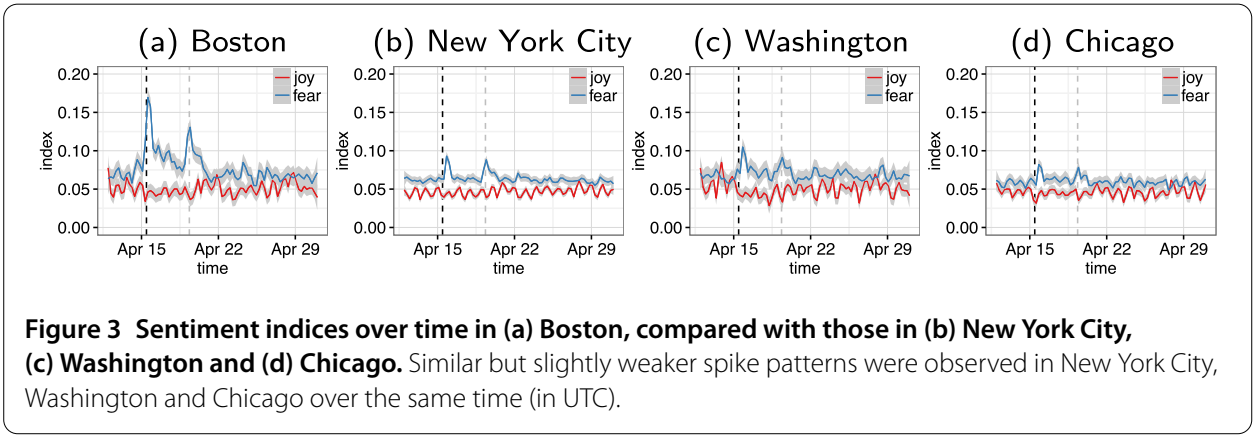

small value $\epsilon=0.1$. So $S_{R T, c}$ will be lower when more tweets contained neither fear nor joy sentiments.

Based on the above calculation, the fear index (or joy index) is a normalized measure of the relative strength of fear (or joy) regardless of number of tweets posted within a region and a time interval.

Figure 2 shows the hourly fear (and joy) indices within DAR and the City of Boston, from April 10 to 30. Compared with joy indices, the fear indices exhibit greater sudden increases around April 15 and April 19, corresponding to the times of the blasts and the subsequent manhunt. The substantial difference between the two indices suggests both that fear was triggered in response to the event and that the lexicon captures the different sentimental expressions.

In Figure 3 we show the sentiment indices in Boston and three other cities: New York City, Washington and Chicago, over the same time period. We observe similar, though slightly weaker, spike patterns in all three cities, where the first peaks on April 15 have a sixto eight-hour delay compared with the first peak in Boston. The highest fear level in Boston is at least 1.5 times the fear level in the other cities. This indicates that, unsurprisingly, the community on which the attacks had a direct impact had stronger and quicker fear responses. Nonetheless, Twitter sentiment captures similar responses in these other major US cities as well.

To test there were significant changes in Twitter users' fearful response after the bombing event, we conduct a paired $t$-test to assess the significance of changes in Twitter users' 
fearful response before and after the event. The fear correlations with Boston are measured within a week before the event and within a week after the event. The test result suggests that there was a significant increase in fear correlation after the event (the sample mean difference is 0.040 with $p$-value $=0.024$ ).

We also observe a small increase in joy in DAR on April 22, which corresponds to the day when the suspect, Dzhokhar Tsarnaev, was charged [20]. The increase in joy is less apparent within the City of Boston more broadly and other major cities. This may suggest that the local community from the directly affected region (DAR) retained higher attention on the bombing related events.

To understand the extent to which a city shares the fear expressed by Boston in response to the event we compute the fear correlation between Boston and the given city in terms of the correlation between the two cities' timeseries of fear indices. Concretely, the correlation is computed by using Spearman's rank correlation coefficient, which measures the strength of two cities' fear indicies increasing or decreasing consistently regardless of the amount. Due to the non-normality of the distribution of cities' fear correlations, we use Box-Cox transformation [84] to determine the use of square root function to transform the variable to normality. In the following analyses, the fear correlations being examined are square-root-transformed.

In Figure 4(a) we plot the cities' transformed fear correlation with Boston against their geographical distance from Boston. The figure shows that the correlation between a city and Boston declines with distance. Washington, New York, and Philadelphia, each of which are within one day's drive or less of Boston, are numbers 3, 4, and 6 most highly correlated with Boston, respectively. Montreal and Toronto, similarly located in driving distance from Boston, are two of the three most highly correlated international cities.

\subsection{Expressions of social support}

In Twitter, hashtags are ubiquitous and flexible annotations allowing users to track ongoing conversations, signal membership in a community, or communicate non-verbal ideas like joy and sadness. Hashtags often reflect eccentric topics and their emergence is happenstance. Novel events often lead to the creation of new hashtags, making their early dynamics observable [85]. Over the two weeks after the Boston Marathon bombings and subsequent events we observe new hashtags such as \#bostonmarathon, \#prayforboston, and \#bostonstrong that were created and quickly adopted by many users in their tweets. These hashtags serve different conversational purposes. For example, \#bostonmarathon is a topical hashtag, most popular on April 15 that was used mainly in the Boston area to indicate any Boston-Marathon-related conversations. We focus on the emergent use of hashtags \#prayforboston and \#bostonstrong. Each hashtag was widely adopted after the bombings and, as described below, substantially used to express emotional content.

\subsubsection{Meaning of the hashtags}

The origins of these hashtags suggest they are used to express different forms of social support for Bostonians. The \#prayforboston hashtag is a variant on the '\#prayfor $\{X\}$ ' hashtags that have been used in recent years in response to various disasters [86]. In response to the riots in London in 2011, [86] find that users largely tweeted messages of general concern and sympathy to the different \#prayfor hashtags associated with that event (\#prayforlondon, \#prayforuk). Tweets to \#prayforboston would thus express feelings associated with 


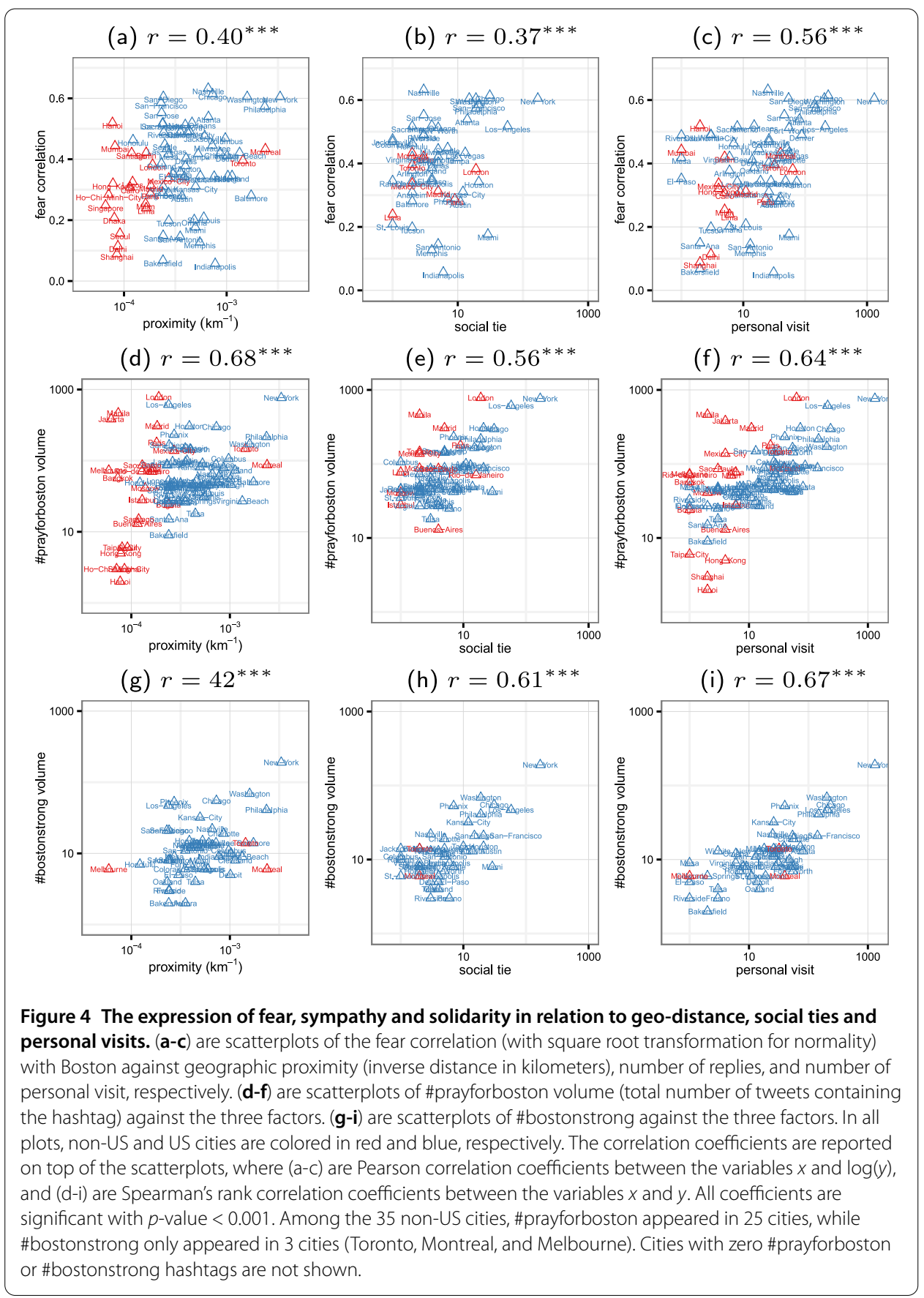

empathic concern, defined as 'an other other-oriented emotional response elicited by and congruent with the perceived welfare of someone else' [87] (pp.145-146). In these tweets individuals may attempt to comfort other people or express concern for their welfare based on the knowledge that these others are in danger or distress.

The \#bostonstrong hashtag is also a variation on an existing phrase used to express feelings toward people under threat or duress. The aim of the expression is not to express concern or to comfort, however. The hashtag is a variation on the phrase ' $\{X\}$ strong' first made popular by Lance Armstrong's 'Livestrong' campaign and later adapted by the US Army for its slogan 'Army Strong' [88]. The sentiment expressed in these phrases is more prop- 
erly described as solidarity. Solidarity is an expression of identification with and pledge to support a community with the aim of ensuring its survival, prosperity or victory in competition with other groups $[16,89]$. Solidarity is often expressed through ritual displays of shared symbols such as flags [16], and focuses on the community and its relationship to external threats. In contrast to expressions of sympathy, expressions of solidarity do not focus on the vulnerability of the group or group members but rather emphasize the group's strength and ability to control its fate [11]. Of particular importance, expressions of solidarity may force individuals to 'choose sides' between groups in a way that is not incumbent on those who simply express sympathy.

With thousands of tweets from thousands of different individuals to each hashtag the meanings of the terms are unlikely to be completely homogeneous or stable over time. Nonetheless, their distinct semantic origins suggest that they each carry different kinds of social support messages. For the sake of simplicity we will refer to the \#prayforboston messages as 'sympathy' messages and the \#bostonstrong messages as 'solidarity' messages.

Despite their different original meanings, it is possible that in the context of the bombings these hashtags largely merged in their usage. To ensure that these hashtags were used to express distinct feelings we conduct a content analysis to qualitatively characterize the tweets posted to them. Since our goal is to see consider whether the hashtags merged into new meanings distinct from their origins, we first used a inductive approach to create themes for a random sample of 200 tweets posted outside of Boston city with either of the hashtags. In the sample set, 100 of the tweets contain the hashtag \#bostonstrong (but not \#prayforboston) and the remaining 100 contain the \#prayforboston (but not \#bostonstrong). To create a coding system, a team (one of the authors and a coder S1) conducted an open coding of the data, allowing codes to emerge, rather than searching for codes based on existing categories. The team iteratively coded the sampled tweets and discussed the codes, coming to agreement on seven themes as listed in Table 2 (with codes A1 to A7). Each theme appeared at least once in the sample. Two of the other coders, S2 and S3, who were not involved in the open coding process, then independently applied these codes to the sampled tweets. These coding results are shown in Figure 5. The inter-coder reliability for the three coders (team, S2, S3) was $83 \%$ for \#bostonstrong tweets, and consistent with expectations, most (83\%) of the sampled tweets with \#bostonstrong were given the codes A1 (celebration), A2 (identify with community) or A3 (regarding community events and rituals), that are associated with solidarity. These codes did not apply well to \#prayforboston, however. The inter-coder reliability for these tweets was low, (36\%) and they were largely distributed away from these themes and toward the more personally sensitive, in particular, A4 (comfort).

Since our goal was to understand whether the hashtags were the same or different, we divide the coding categories into two groups - solidarity (A1-A3) and other (A4-A7). Here the inter-coder agreement improves to 95\% for the tweets with \#bostonstrong, and 96\% for the \#prayforboston tweets. In addition, while $83 \%$ of \#bostonstrong tweets remain in the solidarity category, only $11.7 \%$ of the \#prayforboston tweets fit these solidarity themes. A Pearson's Chi-squared test with Monte Carlo simulation shows that this difference is statistically significant $\left(\chi^{2}=121.28, p<0.0005\right)$. This analysis thus confirms that the two hashtags, when used independently, were used to convey different meanings. See Table 3 for more examples of tweets containing the two hashtags. 
Table 2 Codes used in the analysis

\begin{tabular}{|c|c|c|}
\hline Code & Description & Example(s) \\
\hline$\overline{\mathrm{A} 1}$ & $\begin{array}{l}\text { Positive comments or } \\
\text { anticipation about the progress } \\
\text { of the bombing case, including } \\
\text { appreciation for progress or for } \\
\text { resolving this case/reporting } \\
\text { the progress/celebration }\end{array}$ & $\begin{array}{l}\text { 'Suspect is alive and in custody! \#bostonstrong' } \\
\text { 'To the @Boston_Police ,FBl and State Police, a job well } \\
\text { done. Slainte cheers, what a great start to the weekend. } \\
\text { \#bostonstrong \#thankyou' } \\
\text { 'Toasting a drink to Boston's finest and the best city in } \\
\text { the US with my favorite masshole @SaucyMeats } \\
\text { \#BostonStrong' }\end{array}$ \\
\hline A2 & $\begin{array}{l}\text { Comments related to the } \\
\text { identity of a city of the country, } \\
\text { including love and pride for } \\
\text { Boston or from other } \\
\text { cities/Solidarity as 'American', } \\
\text { 'Bostonian', or 'New England' }\end{array}$ & $\begin{array}{l}\text { 'Watching the Red Sox game even though I hate them. } \\
\text { Gotta show respect to the people of Boston. } \\
\text { \#BostonStrong' } \\
\text { '@BarackObama: We refuse to be terrorized. \#manhunt } \\
\text { \#bostonstrong \#nation @whitehouse' } \\
\text { 'I've never been more proud to be from New England. } \\
\text { \#BostonStrong' }\end{array}$ \\
\hline A3 & $\begin{array}{l}\text { Community events and rituals, } \\
\text { including sport games (Red } \\
\text { Sox, Celtics, players, etc.), } \\
\text { parades, etc. }\end{array}$ & $\begin{array}{l}\text { 'It's like a superbowl parade on the streets of Watertown } \\
\text { with residents thanking \#firstresponders. \#heroes } \\
\text { \#bostonproud \#BostonStrong \#fb' } \\
\text { 'Great pre-game ceremony at Fenway Park } \\
\text { \#BostonStandsAsOne \#BostonStrong and one time only } \\
\text { \#letsgosoxs' }\end{array}$ \\
\hline A4 & $\begin{array}{l}\text { Expressing concern, emotion } \\
\text { (empathy, sorrow, anger, } \\
\text { confusion, terrified feelings, } \\
\text { etc), comfort, or wishes for } \\
\text { good outcomes regarding } \\
\text { bombing or people } \\
\text { loved/affected }\end{array}$ & $\begin{array}{l}\text { 'Can't sleep. What an awful day for Boston and America.. } \\
\text { \#prayforboston' } \\
\text { 'Damn! Now } 3 \text { people announced dead. I'm legit getting } \\
\text { really angry now \#prayforboston' } \\
\text { 'The thought of people I love being in that kind of } \\
\text { danger alone makes me so sick. I LOVE you all } \\
\text { \#prayforboston' } \\
\text { 'Keeping Boston in my prayers \#prayforboston' }\end{array}$ \\
\hline A5 & $\begin{array}{l}\text { Comments with a viewpoint, } \\
\text { expressing a perspective that } \\
\text { can be used to consider or } \\
\text { experience the bombing } \\
\text { events or calling for actions } \\
\text { using a particular perspective }\end{array}$ & $\begin{array}{l}\text { 'Sometimes you just have to be thankful that you at least } \\
\text { made it to today. Someone else might not have been as } \\
\text { fortunate \#prayforboston' } \\
\text { 'Was gonna tweet about how much I hate waking up for } \\
\text { class but the fact that I get to wake up each day is a } \\
\text { privilege \#PrayForBoston' } \\
\text { 'It's truly eye-opening when the unimaginable hits so } \\
\text { close to home. To think some live w/ such fear everyday } \\
\text { \#prayforboston \#prayforhumanity' }\end{array}$ \\
\hline A6 & Questioning 'prayforboston' & $\begin{array}{l}\text { 'For those who say thoughts and prayers for Boston, } \\
\text { actually say a prayer and not just make a status for the } \\
\text { attention \#prayforboston' }\end{array}$ \\
\hline A7 & $\begin{array}{l}\text { Cynical or condemning } \\
\text { comments }\end{array}$ & $\begin{array}{l}\text { 'You go to watch a movie, you get shot. You go to } \\
\text { school, you get shot. You run a marathon, you get } \\
\text { bombed \#WelcomeToAmerica \#PrayForBoston' }\end{array}$ \\
\hline
\end{tabular}

\subsubsection{How did these two hashtags relate to fear and other variables?}

The distinct nature of these hashtags makes it likely that there are geographic differences in their use. In particular, while the generic nature of sympathy (as expressed by \#prayforboston) might not have any geographic specificity, expressions of solidarity (using \#bostonstrong) would be expected from cities with deeper ties to Boston that include shared regional or cultural identities.

As described above, the first hashtag \#prayforboston became popular immediately after the bombings. The second hashtag \#bostonstrong was populated two days after and gained its highest popularity around April 20 due to the 'Boston Strong' community 


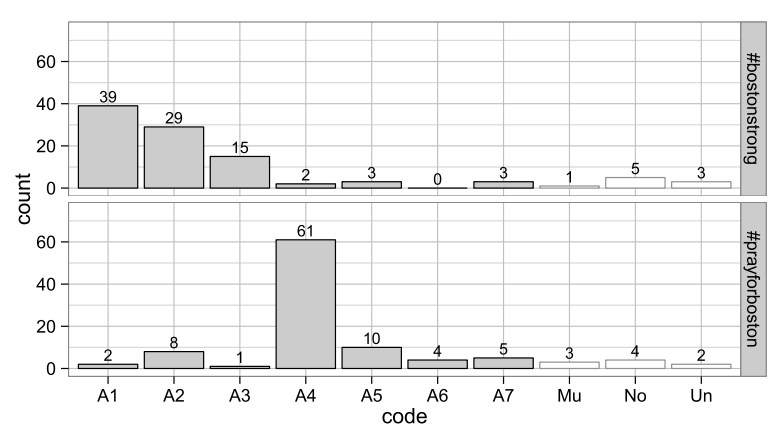

Figure 5 Frequency of categories associated with the two hashtags. Most (83\%) of the sampled tweets with \#bostonstrong were given the code $\mathrm{A} 1, \mathrm{~A} 2$ and $\mathrm{A} 3$. The majority of the sampled tweets with \#prayforboston were given the code A4, and some were coded as A5, A6 and A7. In rare cases, a tweet cannot be assigned to one of the seven codes, which include: $(\mathrm{Mu})$ Multiple codes: the coders agreed that more than one code can apply to the tweet; (No) No agreement: the coders did not reach an agreement for the code(s) of the tweet; (Un) Uncodable: the coders did not understand the content of the tweet.

Table 3 Example tweets during Boston bombings

\begin{tabular}{|c|c|c|}
\hline Fear & \#prayforboston & \#bostonstrong \\
\hline $\begin{array}{l}\text { [Boston] Emergency situation!!! } \\
\text { Everybody gets out the station!!!! } \\
\text { \#boston \#mbta \#suck (@ MBTA } \\
\text { Park Street Station - @mbtagm) } \\
\text { http://t.co/hMTm908kMc } \\
\text { [Boston] Theyre blowing shit up in } \\
\text { Boston now? Keep that shit outta } \\
\text { here } \\
\text { [NY] What a scary scene in } \\
\text { Boston...... Bet it was a terrorist } \\
\text { attack } \\
\text { [Washington] What the hell just } \\
\text { happened in Boston } \\
\text { [Denver] Bombing in Boston?! } \\
\text { Damn, the world is just all fucked } \\
\text { up now. } \\
\text { [Montreal] @MTLDaniel in Boston } \\
\text { no and in the united states at this } \\
\text { point HELL NOOOO }\end{array}$ & $\begin{array}{l}\text { [Boston] \#PrayForBoston how } \\
\text { could you sick fucks bomb my } \\
\text { hometown } \\
\text { [NY] so glad the few people i } \\
\text { know in boston are okay. } \\
\text { \#prayforboston \#staysafe } \\
\text { \#devastating } \\
\text { [Washington] Sure glad I'm not in } \\
\text { \#Boston like I was supposed to be } \\
\text { this weekend. Love you } \\
\text { @SarahM152 \#prayforboston } \\
\text { \#bostonmanhunt } \\
\text { [Denver] The acts of violence } \\
\text { done by the people that attack } \\
\text { others are unforgivable. We need } \\
\text { to spread love around the world. } \\
\text { \#prayforboston } \\
\text { [Montreal] Thank God my family } \\
\text { up in Boston is alright!! } \\
\text { \#prayforboston rest in peace to } \\
\text { these } 2 \text { souls that left us today. }\end{array}$ & $\begin{array}{l}\text { [Boston] @GreshandZo time to } \\
\text { show the world why Boston truly } \\
\text { is a great city. You know we will } \\
\text { respond the way a city should. } \\
\text { \#BostonStrong } \\
\text { [NY] Rivalry over? @Yankees: } \\
\text { \#Yankees fans show their support } \\
\text { for Boston. \#BostonStrong } \\
\text { [Washington] '@ValaAfshar: WE } \\
\text { WILL RUN AGAIN. \#bostonstrong' - } \\
\text { Absolutely. And with more pride } \\
\text { than ever! } \\
\text { [Denver] Such an emotional week } \\
\text { for this country. Never been more } \\
\text { proud to be an American. } \\
\text { \#BOSTONSTRONG \#WestTX } \\
\text { [Montreal] @blaisp } \\
\text { @Anthony_Milano merci! } \\
\text { Beautiful day to run a fun race in } \\
\text { Montreal! \#bostonstrong } \\
\text { \#runforboston }\end{array}$ \\
\hline
\end{tabular}

events. Similar to the detected fear, the use of the two hashtags exhibit a correlation with the geographic proximity of cities, as shown in Figure 4(d,g). And similar to the expression of fear, and despite their focus on Boston, the two hashtags also appeared widely in tweets from other cities. Outside Boston, the level of interest among Twitter users in expressing sympathy (in terms of \#prayforboston volume) and solidarity (in terms of \#bostonstrong volume) varies. As expected from their meaning, the \#prayforboston had a wider reach than \#bostonstrong. In particular, among the 35 non-US cities considered in this analysis, \#prayforboston appeared in 25 cities, while \#bostonstrong only appeared in 3 cities (Toronto, Montreal, and Melbourne). In Figure 4(d-i), cities with zero \#prayforboston or \#bostonstrong hashtags are not shown. 


\subsection{Examining factors through prediction}

To better understand the antecedents and mechanisms that give rise to these ripples of feeling we examine city level differences in the use of fear language, \#prayforboston, and \#bostonstrong on three community-community dimensions that pre-date the attacks: geographical distance from Boston, social connections to Boston, and residents' direct, physical experiences with Boston. These dimensions are captured from our data as follows.

(a) Geographic distance (or geo) is the distance between Boston and a given city, measured in kilometers. In the analyses, the inverse of distance - geo-proximity - is used to facilitate comparison.

(b) Social tie (or social) is the strength of social connections maintained over social media between Boston and a given city. We quantify the social tie strength between two cities $A$ and $B$ based on the number of replies sent within approximately the two weeks that precede the event (from April 2 to 14), with a condition that the reply sender and receiver were observed in cities $A$ and $B$ or $B$ and $A$ on the same day of the reply. A user can be observed in a city if s/he posts a tweet with geocode within the region of the city.

(c) Personal visit (or visit) is the amount of travel users made between cities. We use personal visits between Boston and a given city to quantify the direct experience or actual familiarity of being in Boston. We first extract a transition flow for each individual user within the two-week pre-event period (from April 2 to 14). The transition flow is a temporal ordered list of cities where the given user was observed through geocoded tweets. The amount of travel between two cities $A$ and $B$ is then measured based on the number of transitions between $A$ and $B$ or $B$ and $A$ by aggregating all individual transition flows.

We selected this quantity to capture cities' relative differences in the number of active Twitter users who traveled between the cities (before the event). The benefit of using this technique is that it directly measures the geographic flow of the activity we are interested in - tweeting. Indirect measures of personal flow between cities, such as provided by commuting flows or airline traffic, are largely based on non-Twitter users, and thus introduce an additional layer of interpretation. These indirect measures also fail to capture all relevant geographic and temporal patterns. For example, airline data does not capture traffic between cities via other means, such as automobile, and publicly available airline traffic data captures individuals' start and endpoints, but does not include layovers. Our measure captures up-to-date personal visits between cities via any mode of transportation and including any form of exposure, including time spent traveling through Boston on the way between two other locations.

Despite these advantages, this two-week short-term time window has a limitation due to the small portion of geocoded tweets compared to the total tweets, giving it the potential to be noisy. It was possible that some cities would score higher than others due to random variation, or that many cities would have no visits at all. However, only 11 cities, and only 3 US cities, had no visits, with 31 cities having at least 25 visits and as many as 1,300 (New York). We thus concluded that statistically significant correlations observed between this measure and our other indices would be sound indicators of real relationships. 
In general, aggregate measures of a city can largely depend on the city size. In our study, since all aggregate variables are measured from Twitter, the important measure of population is the number of Twitter users in the cities and the level of the users' activity rather than the actual city size. For example, we would expect that the number of fearful tweets would be much greater in a city in which there are a large number of heavily active users than in a city with few users, even if the city with few users had a larger total population. Furthermore, research on tweet behavior during disasters suggests that tweet activity spikes in response to emergency situations, with those who perceive themselves to be more directly affected showing greater activity [40]. Since it is the aim of this study to determine where those who are more directly effected are geographically, the analysis must account for these spikes occurring in any or all of our cities. Thus, while including raw tweet activity has the potential to introduce noise to our analysis, undermining the possibility of obtaining statistically significant results, ignoring such spikes would potentially introduce substantial bias. Hence, we consider the following control variable that reflects both the city size and its activity in the Twitter space:

(d) Tweet activity (or Tweets) is the pre-event expected Twitter activity of a city regardless of the event. This quantity serves as a baseline variable when explaining the level of response to the bombing events. We quantify this baseline tweet activity by the number of tweets posted from a city within the two-week pre-event period. Importantly, tweet activity can fluctuate substantially within short time periods due to retweet spikes and other short-lived trends, thus potentially introducing noise to this measure.

In Figure 4 we plot the fear correlation (with square root transformation), the volume of \#prayforboston and \#bostonstrong against the geo-proximity, social tie and personal visit between Boston and other cities. The fear correlation is computed based on fear indices between April 15 and 21. The volumes of hashtags are calculated as total number of tweets containing the hashtags posted between April 15 and 30. The first-order correlations are shown on top of each scatterplot. We compute Pearson correlation coefficients for correlations between the transformed fear correlation and the three variables, and compute Spearman's rank correlation coefficients for correlations involving the hashtag counts (the volumes of \#prayforboston and \#bostonstrong) due to their skewed distributions.

All three factors are significantly associated with shared fear. Among the three factors, personal visit has the highest association with shared fear, with a correlation substantially greater than the other two. All three factors also have a significant correlation with the use of the social support hashtags, however, the differences are not as stark. For \#bostonstrong, personal visit also has the highest value, but it is only modestly greater than social ties, and for \#prayforboston, geography has the highest correlation but it is only slightly higher than personal visits.

These first order correlations suggest that there is a robust city-to-city relationship in the expression of fear and the different forms of social support. A substantial portion of the variance with which individuals in one city tweet similarly to individuals in another can be explained in spatial terms, social terms, or a distinct combination of the two (visits). These factors are themselves likely to be highly correlated, however, making it difficult to see if they operate independently. In particular, both social ties and personal visits may be consequences of geography or one another. 
Table 4 Summary of models and included variables

\begin{tabular}{lllllllll}
\hline Variables & Models & & & & & & & \\
\cline { 2 - 8 } & Baseline & Geo & Social & Visit & Geo-social & Geo-visit & Social-visit & Full \\
\hline Tweets & $\times$ & $\times$ & $\times$ & $\times$ & $\times$ & $\times$ & $\times$ & $\times$ \\
Geo & & $\times$ & & & $\times$ & $\times$ & & $\times$ \\
Social & & & $\times$ & & $\times$ & & $\times$ & $\times$ \\
Visit & & & & $\times$ & & $\times$ & $\times$ & $\times$ \\
\hline
\end{tabular}

Table 5 Regression on fear

\begin{tabular}{lll}
\hline & Full & Best \\
\hline Tweets & $-0.050(0.020)^{*}$ & $-0.051(0.019)^{* *}$ \\
Geo & $0.014(0.021)$ & $0.015(0.021)$ \\
Social & $-0.008(0.028)$ & \\
Visit & $0.132(0.030)^{* * *}$ & $0.127(0.023)^{* * *}$ \\
Adj. $R^{2}$ & 0.340 & 0.347 \\
Os. $R^{2}$ & 0.317 & 0.325 \\
\hline
\end{tabular}

The standardized coefficients, standard errors (in parentheses), adjusted $R^{2}$ and out-of-sample $R^{2}$ for the full model and the best (geo-visit) model.

We use multivariate regression analyses to differentiate these potential explanations. We use linear regression for the level of shared fear and Poisson regression for the count of sympathy (\#prayforboston) and the count of solidarity (\#bostonstrong). To find the most important variables, we create the following models with different combination of predictors:

- baseline model: has a single predictor, tweet activity;

- geo model: has two predictors, tweet activity and geo-proximity;

- social model: has two predictors, tweet activity and social tie;

- visit model: has two predictors, tweet activity and personal visit;

- geo-social model: has three predictors, tweet activity, geo-proximity and social tie;

- geo-visit model: has three predictors, tweet activity, geo-proximity and personal visit;

- social-visit model: has three predictors, tweet activity, social tie and personal visit;

- full model: has four predictors, tweet activity, geo-proximity, social tie and personal visit.

Table 4 summarizes the list of models and their included variables. We compare the performance of these models in order to determine the most important variables in predictive models by taking the relationship among variables into consideration. We report the results of this analysis in the following sections.

\section{Results}

\subsection{Explaining shared fear}

We compare how different factors can explain the variance of shared fear in different cities by using linear models. All predictors are log-transformed and standardized. Table 5 reports the regression results for the full model (containing all four predictors) and the best model - the geo-visit - model selected as the model with the best out-of-sample $R^{2}$. In both models for explaining fear, the predictor 'visit' has a strong and significant effect, but the other two variables ('geo' and 'social') are not significant when personal visits are controlled for, though geography does make a modest contribution to the best model. 


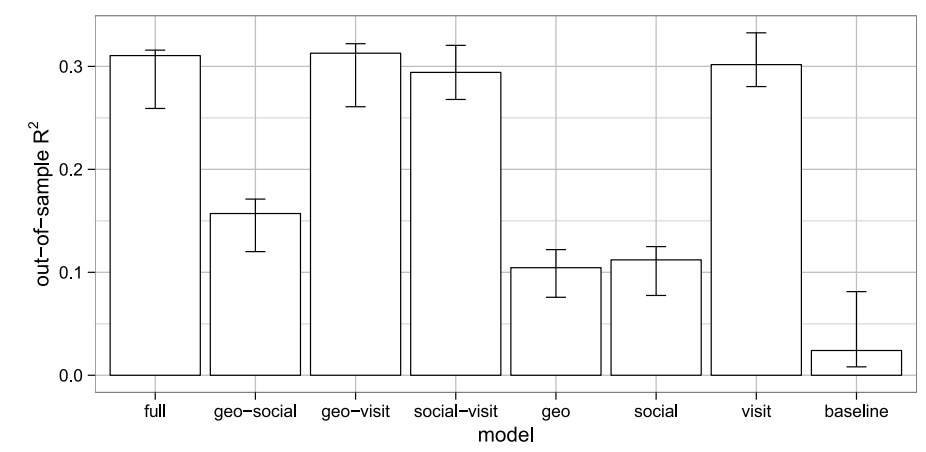

Figure 6 Out-of-sample $\boldsymbol{R}^{2}$ for models of predicting shared fear. Models including the 'visit' predictor perform significantly better than others. Error bars show the bootstrapped 95\% confidence intervals of the out-of-sample $R^{2}$.

To further assess the quality of model, we compute out-of-sample $R^{2}$ through 20-fold cross-validation and compute the confidence interval for each out-of-sample $R^{2}$ by using bootstrap resampling based on 1,000 replications and compute the bootstrap percentile confidence interval at $95 \%$ level of confidence. This model assessment is deployed to be robust to the potential influence of outlier cities. The results, shown in Figure 6, indicate that models including the 'visit' predictor perform significantly better than models without 'visit', confirming the central importance of direct experience with a city in explaining expressions of fear when that city is attacked. These results do not suggest that social factors or geographic factors are not important but rather point more specifically to the mechanism through which they are important. Geographic proximity appears to play a role because it encourages personal visits. Social ties may also encourage visits. Alternatively, direct experiences may lead to diffusion over other channels, such as interest in reports from mass media or face-to-face conversations.

\subsection{Explaining social support}

Fear is associated with a lack of control in the face of threat while expressions of social support, particularly for distant others, can emerge from a variety of sources [3, 12]. This raises the question as to whether expressions of social support are better explained by the other factors, particularly the social factor. Below we compare how different factors can explain the variance of social support in different cities.

Because the volumes of the \#prayforboston and \#bostonstrong hashtags are overdispersed count variables we use quasi-Poisson regression instead of linear regression to examine the impact of different factors. The quasi-Poisson regression is a common approach to deal with overdispersion for count data and is based on a generalized linear model framework [90] with the so-called quasi-likelihood estimation. The quasi-Poisson regression does not have an equivalent to the $R^{2}$ found in ordinary least square regression. For the purpose of model comparison, we calculate pseudo $R^{2}$, and the out-of-sample pseudo $R^{2}$ with bootstrapped confidence intervals by using cross-validation and bootstrap resampling as described above.

Solidarity. Table 6 shows regression results for explaining the variance in the volume of use of the hashtag \#bostonstrong. Interestingly, the most effective predictor in the full model and the best model seem to be inconsistent. The 'visit' predictor appears to be 
Table 6 Regression on \#bostonstrong

\begin{tabular}{lll}
\hline & Full & Best \\
\hline Tweets & $-0.086(0.185)$ & $0.007(0.178)$ \\
Geo & $0.077(0.064)$ & $0.219(0.064)^{* *}$ \\
Social & $0.218(0.169)$ & $0.746(0.142)^{* * *}$ \\
Visit & $0.903(0.208)^{* * *}$ & \\
Pseudo $R^{2}$ & 0.878 & 0.828 \\
Os. $R^{2}$ & 0.452 & 0.583 \\
\hline
\end{tabular}

The standardized coefficients, standard errors (in parentheses), adjusted $R^{2}$ and out-of-sample $R^{2}$ for the full model and the best (geo-social) model.

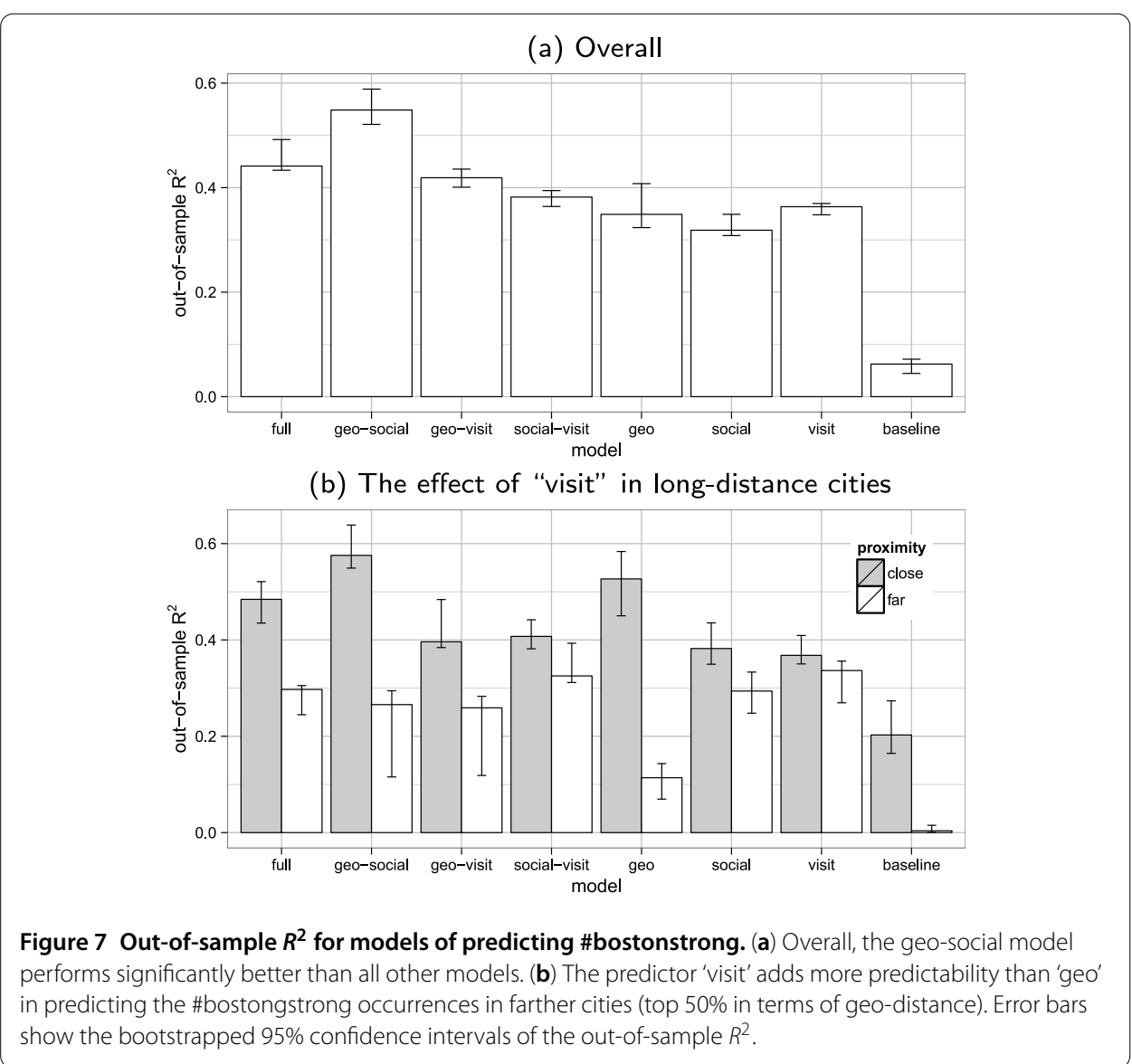

strong and significant in the full model, but the geo-social model (without 'visit' predictor) performs significantly better than all other models (Figure 7(a)). We suspect that there might be a moderator effect that leads to such inconsistency. To test whether geographical proximity could be the moderator, we split the cities into two equal-size groups based on their geographic proximity to Boston. After decomposing the cities into the two groups, the effect of predictors become consistent in the full and best models in both sets, suggesting the geographical proximity moderates the effect of 'visit' in these models. The results are shown in Figure 7(b). We see the predictors 'geo' and 'social' appear to be effective in predicting the use of \#bostongstrong in cities in the 'close' group. This effect disappears, however, for the 'far' groups, where the 'visit' predictor takes the place of the 'geo' predic- 
Table 7 Regression on \#prayforboston

\begin{tabular}{lll}
\hline & Full & Best \\
\hline Tweets & $0.955(0.100)^{* * *}$ & $0.963(0.099)^{* * *}$ \\
Geo & $-0.055(0.054)$ & \\
Social & $0.048(0.114)$ & $0.046(0.113)$ \\
Visit & $0.387(0.131)^{* *}$ & $0.327(0.117)^{* * *}$ \\
Pseudo $R^{2}$ & 0.717 & 0.699 \\
Os. $R^{2}$ & 0.386 & 0.390 \\
\hline
\end{tabular}

The standardized coefficients, standard errors (in parentheses), adjusted $R^{2}$ and out-of-sample $R^{2}$ for the full model and the best (social-visit) model.

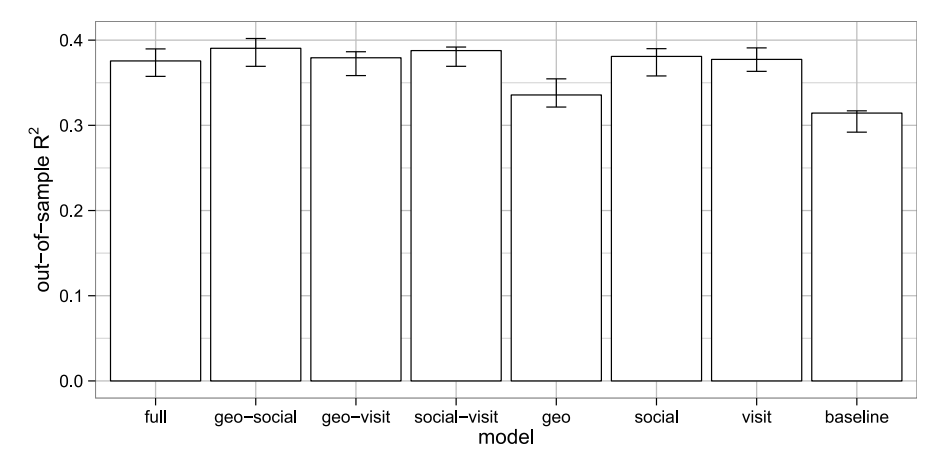

Figure 8 Out-of-sample $\boldsymbol{R}^{2}$ for models of predicting \#prayforboston. Models including the 'visit' or 'social' predictor perform slightly better than the baseline and geo models. However, the predictability of the two predictors is not differentiable. Error bars show the bootstrapped $95 \%$ confidence intervals of the out-of-sample $R^{2}$.

tor in the best model. Thus, for solidarity, geographic proximity moderates the effect of 'visit' in the overall results, which explains the inconsistency in Table 6.

Sympathy. Table 7 shows the regression results for explaining the variance in the volume of use of the hashtag \#prayforboston. The predictor 'visit' seems to be a strong and significant predictor. The social-visit model performs the best but it is not significantly better than other models. As shown in Figure 8, models including the 'visit' or 'social' predictor all perform similarly - slightly better than the baseline and geo models. The predictability of the 'visit' and 'social' predictors is not differentiable, though the 'visit' predictor tends to take over in a model including both predictors, as shown in Table 7.

Our analyses involve both US and non-US cities. To see whether the results are an artifact of the varying English speaking populations in different countries, we restrict our analysis to the US cities only. The results for US cities (as shown in Tables 8, 9, 10) resemble the overall patterns we discovered from all the 95 cities (Tables 5, 6, 7).

\subsection{Fear and social support}

We further examine how fear itself is associated with expressions of social support. We first compute the correlations between shared fear and the two types of social support in terms of Spearman's rank correlation coefficients. As shown in Table 11, the level of shared fear has higher correlation with \#bostonstrong volume $(r=0.532, p<0.001)$ than with \#prayforboston volume $(r=0.253, p<0.001)$. Furthermore, the correlation between shared fear and \#bostonstrong volume remains significant $(r=0.253, p=0.014)$ when partialling out the four predictors ('tweets', 'geo,' 'social' and 'visit'), while the partial 
Table 8 Regression on fear (US only)

\begin{tabular}{lc}
\hline & Full (Best) \\
\hline Tweets & $0.044(0.036)$ \\
Geo & $0.003(0.024)$ \\
Social & $-0.045(0.034)$ \\
Visit & $0.094(0.040)^{*}$ \\
Adj. $R^{2}$ & 0.251 \\
Os. $R^{2}$ & 0.227 \\
\hline
\end{tabular}

The standardized coefficients, standard errors (in parentheses), adjusted $R^{2}$ and out-of-sample $R^{2}$ for the full model, which is also the best model.

Table 9 Regression on \#bostonstrong (US only)

\begin{tabular}{lll}
\hline & Full & Best \\
\hline Tweets & $0.209(0.155)$ & $0.339(0.147)^{*}$ \\
Geo & $0.121(0.065) \cdot$ & $0.182(0.060)^{* *}$ \\
Social & $0.185(0.173)$ & $0.377(0.161)^{*}$ \\
Visit & $0.462(0.215)^{*}$ & \\
Pseudo $R^{2}$ & 0.887 & 0.866 \\
Os. $R^{2}$ & 0.542 & 0.655 \\
\hline
\end{tabular}

The standardized coefficients, standard errors (in parentheses), adjusted $R^{2}$ and out-of-sample $R^{2}$ for the full model and the best (geo-social) model.

Table 10 Regression on \#prayforboston (US only)

\begin{tabular}{lrl}
\hline & \multicolumn{1}{l}{ Full } & Best \\
\hline Tweets & $0.705(0.057)^{* * *}$ & $0.706(0.054)^{* * *}$ \\
Geo & $-0.001(0.025)$ & \\
Social & $0.005(0.066)$ & $0.005(0.065)$ \\
Visit & $0.141(0.079)$. & $0.140(0.069)^{*}$ \\
Pseudo $R^{2}$ & 0.974 & 0.974 \\
Os. $R^{2}$ & 0.657 & 0.668
\end{tabular}

The standardized coefficients, standard errors (in parentheses), adjusted $R^{2}$ and out-of-sample $R^{2}$ for the full model and the best (social-visit) model.

Table 11 Correlations between social support and fear

\begin{tabular}{lll}
\hline & \#bostonstrong & \#prayforboston \\
\hline Fear & $0.532^{* * *} ; 0.253^{* *}$ & $0.355^{* * *} ; 0.135$ \\
\#bostonstrong & & $0.488^{* * *} ; 0.156$ \\
\hline
\end{tabular}

The rank correlations between fear, \#bostonstrong and \#prayforboston. The second value is the rank correlation partialling out the four predictors (tweets, geo, social and visit).

correlation between shared fear and \#prayforboston volume become negligible ( $r=0.135$, $p=0.202)$.

We incorporate the level of shared fear into the quasi-Poisson regression models for explaining the \#bostonstrong volume and \#prayforboston volume, respectively. The results, as shown in Table 12, indicate that 'fear' is indeed significantly associated with \#bostonstrong but not \#prayforboston. Holding other predictors constant, cities that express fear in line with Boston in response to the attacks tend to express more solidarity with Boston in the aftermath. In contrast, cities that express fear in line with Boston are not necessarily the cities that express the sympahty for Bostonians associated with \#prayforboston. 
Table 12 Regression on social support with fear

\begin{tabular}{lcc}
\hline & Full (\#bostonstrong) & Full (\#prayforboston) \\
\hline Tweets & $-0.032(0.198)$ & $0.990(0.114)^{* * *}$ \\
Geo & $0.095(0.064)$ & $-0.051(0.054)$ \\
Social & $0.281(0.181)$ & $0.050(0.116)$ \\
Visit & $0.600(0.250)^{*}$ & $0.315(0.166) \cdot$ \\
Fear & $0.343(0.164)^{*}$ & $0.080(0.113)$ \\
Pseudo $R^{2}$ & 0.889 & 0.718 \\
Os. $R^{2}$ & 0.492 & 0.378 \\
\hline
\end{tabular}

The standardized coefficients, standard errors (in parentheses), pseudo $R^{2}$ and out-of-sample $R^{2}$ for the full models for predicting \#bostonstrong and \#prayforboston. The 'fear' variable has significantly positive association with \#bostonstrong but not \#prayforboston.

\section{Discussion}

The goal of this study was to better understand the relationships that motivate the expression of fear and social support from geographically distant communities in response to a terrorist attack on one particular city. Our primary finding is that while synchronous expressions of fear are associated at once with shared geography, social network ties, and direct personal experience between cities, direct personal experience represents the dominant relationship. When this direct experience is controlled for, the relationships between fear and geography and fear and more 'virtual' social contact via social media are eliminated.

This finding has both practical and theoretical implications. For the practical purposes of first responders or government agencies seeking to reduce or quell fear in neighboring populations after a terrorist attack this finding suggests that fear will spread to those communities with the most direct personal experience with the focal area.

Theoretically, it suggests that the 'ripples' of fear have a physical component, even over large distances where there is not likely to be a direct, physical threat. While risk researchers have emphasized the variety of social and symbolic channels that play a role in the spread of responses to risk and threats, these findings suggest that many of these social relations are nonetheless grounded in concrete, physical relations. In particular, despite the importance of social media and other virtual connections between cities, the social and/or personal contexts of shared fear correspond to shared physical interactions. This effect may have both geo-spatial and social components. Direct visits between communities may be a more effective measure of their effective spatial proximity, capturing the ease with which citizen can get from one place to another through accessible transportation. For example, people in Chicago may have expressed fear more in line with Boston than people in Indianapolis (which is slightly closer to Boston) because, as a major airline hub, Chicago may receive more traffic from Boston.

Personal visits may also reflect social proximity, where this social proximity has a physical element - if an individual had been to Boston recently they were likely to have interacted directly with friends or relatives for whom they feared after the attacks. Thus the extent of 'corporeal' social exchange - the number of people that move back and forth between the communities - may reflect a deeper set of social, cultural and economic ties that go beyond sharing information and other forms of virtual communication to include senses of shared community or identity. For example, comparing London and Montreal in terms of sharing fear with Boston, the many additional virtual social relationships between Lon- 
don and Boston did not contribute to the fear that Londoners experienced since London and Montreal are roughly equivalent in personal visits to Boston.

The analyses of social support shed further light on these explanations. Perhaps most interesting is the relationship between the predictors of fear, the expression of fear, and the expression of solidarity with Boston. Communities that expressed more fear also expressed more solidarity with Boston, and this variable, combined with personal visits, is the best predictor of solidarity expression. This provides evidence, consistent with the findings of [11], that fear can be experienced through an attack on one's group irrespective of whether one feels personally in danger. Indeed, without fear as a predictor, solidarity is best predicted by the geo-social model for 'close' cities, and US cities dominate the top solidarity measurement, suggesting that for some communities, the attack on Boston was a broader attack on a symbolic group - such as the US as a whole. [16, 29]. Including fear as a predictor elicits the responses of those who are inclined to identify with Boston but may not follow more typical mobility patterns.

Moreover, whether individuals consider their city to be in the same 'group' as Boston may also be useful for interpreting the predictors of the sympathy expressed using \#prayforboston. The \#prayforboston hashtag was, like fear, best predicted by personal visits, but its usage shows a weak correlation with fear itself. London, for example, was modest in its expression of fear but very forthcoming in its use of \#prayforboston, perhaps as the result of that city itself having recently been the target of a terrorist attack. This suggests that, in contrast to the strong relationship between fear and shared identity, sympathy is extended outside of one's own group.

From a practical perspective, these findings suggest that not all fear is necessarily bad. Fear in surrounding communities may actually play a somewhat productive role in awakening their solidarity with a community directly targeted by terrorism. This finding is interesting for considering the general prospects of terrorism as a strategy for political change in the era of social media. Whereas in past eras, terrorism may have encouraged feelings of solidarity amongst distant others, there were few avenues through which these distant others could demonstrate their solidarity to the targeted community and one another.

\section{Conclusion and future work}

In this work, we study the expression of fear and social support in Twitter communication during and after a terrorist attack. Using about 180 million, nearly all geotagged, tweets we examine the temporal correlation in these expressions between Boston and other cities. Our findings have implications both for identifying vulnerable populations and encouraging community resilience in response to terrorist attacks.

Our current work presents several limitations. First, we rely on a concept-based affective lexicon that does not capture fear signals in non-English words or in more dynamic forms (such as emoticons and acronyms). Future work will include human-coded content analysis to identify expressions not captured in fixed dictionaries. Second, this paper focused on the city-level aggregated statistics but did not include potentially important social, political and economic attributes of these cities which will be included in future analyses.

The connections we reveal between the dynamics of fear communications and human mobility have important consequences for understanding the spread of information and 
emotions across populations. Further investigation of such connections, including the characterization of the shared fears at multiple scales of time and space, may prove fruitful in a number of areas including crisis management, information diffusion, and social contagion.

\section{List of abbreviations used \\ DAR, directly affected region.}

\section{Competing interests}

The authors declare that they have no competing interests.

\section{Authors' contributions}

Conceived \& designed: YRL, DM; Analyzed the data: YRL; Contributed analysis tools: YRL; Wrote the manuscrpt: YRL, DM.

\section{Author details}

'School of Information Sciences, University of Pittsburgh, Pittsburgh, PA 15260, USA. 'Department of Communication, Cornell University, Ithaca, NY 14850, USA.

\section{Acknowledgements}

This work is part of the project supported by NSF grant \#1423697. Special thanks go to Wen-Ting Chung, Alice Renegar and Marisa Gianfortune for their help in the coding process and valuable feedback. We would also like thank David Lazer, Louise Comfort and Peggy Koenig for providing comments during the early stage of this work. Any opinions, findings, and conclusions or recommendations expressed in this material are those of the authors and do not necessarily reflect the views of the funding source.

\section{Endnote}

a http://developer.yahoo.com/geo/geoplanet/guide/api-reference.html.

Received: 16 April 2014 Accepted: 16 October 2014 Published online: 05 November 2014

\section{References}

1. Sunstein CR (2003) Terrorism and probability neglect. J Risk Uncertain 26(2-3):121-136.

2. Dowling RE (1986) Terrorism and the media: a rhetorical genre. J Commun 36(1):12-24.

3. Lerner JS, Keltner D (2001) Fear, anger, and risk. J Pers Soc Psychol 81(1):146-159. doi:10.1037/0022-3514.81.1.146

4. Paterson RJ, Neufeld RW (1987) Clear danger: situational determinants of the appraisal of threat. Psychol Bull 101(3):404

5. Kasperson RE, Renn O, Slovic P, Brown HS, Emel J, Goble R, Kasperson JX, Ratick S (1988) The social amplification of risk: a conceptual framework. Risk Anal 8(2):177-187.

6. Slovic P (1987) Perception of risk. Science 236(4799):280-285.

7. Dougall AL, Hayward MC, Baum A (2005) Media exposure to bioterrorism: stress and the anthrax attacks. Psychiatry 68(1):28-42

8. Sutton J, Palen L, Shklovski I (2008) Backchannels on the front lines: emergent uses of social media in the 2007 southern California wildfires. In: ISCRAM2008, pp 624-632

9. Coviello L, Sohn Y, Kramer ADI, Marlow C, Franceschetti M, Christakis NA, Fowler JH (2014) Detecting emotional contagion in massive social networks. PLoS ONE 9(3):e90315. doi:10.1371/journal.pone.0090315

10. Kramer ADI, Guillory JE, Hancock JT (2014) Experimental evidence of massive-scale emotional contagion through social networks. Proc Natl Acad Sci USA 111(24):8788-8790. doi:10.1073/pnas.1320040111

11. Mackie DM, Devos T, Smith ER (2000) Intergroup emotions: explaining offensive action tendencies in an intergroup context. J Pers Soc Psychol 79(4):602-616. doi:10.1037//0022-3514.79.4.602

12. Lerner JS, Gonzales RM, Small DA, Fischoff B (2003) Effects of fear and anger on perceived risks of terrorism: a national field experiment. Psychol Sci 14(2):144-150

13. Maitner AT, Mackie DM, Smith ER (2006) Evidence for the regulatory function of intergroup emotion: emotional consequences of implemented or impeded intergroup action tendencies. J Exp Soc Psychol 42(6):720-728. doi:10.1016/j.jesp.2005.08.001

14. Lazarus RS (2006) Emotions and interpersonal relationships: toward a person-centered conceptualization of emotions and coping. J Pers 74(1):9-46. doi:10.1111/j.1467-6494.2005.00368.x

15. Apolone G, Mosconi P (2002) Post-traumatic stress disorder. N Engl J Med 346(19):1495.

16. Collins R (2004) Rituals of solidarity and security in the wake of terrorist attack. Sociol Theory 22(1):53-87

17. Noelle-Neumann E (2002) Terror in America: assesments of the attacks and their impact in Germany. Int J Public Opin Res 14(1):93-98

18. CNN Staff (2013) What we know about the Boston bombing and its aftermath. http://www.cnn.com/2013/04/18/us/boston-marathon-things-we-know/index.html. Accessed 2013-09-15

19. Globe Staff (2013) 102 hours in pursuit of Marathon bombing suspects - The Boston Globe. https://www.bostonglobe.com/metro/2013/04/28/bombreconstruct/NbSZhzHm35yR88EVmVdbDM/story.html. Accessed 2014-04-10

20. Markon J, Horwitz S, Johnson J (2013) Dzhokhar Tsarnaev charged with using 'weapon of mass destruction'11. The Washington Post. Chap. National. Accessed 2013-09-15

21. Dubois L, News NBC (2013) 'Boston Strong' emerges as rallying cry, from stadiums to tweets. http://usnews.nbcnews.com/_news/2013/04/21/17850375-boston-strong-emerges-as-rallying-cry-from-stadiumsto-tweets. Accessed 2014-04-10 
22. Feinsand M (2013) Boston Marathon bombings: Yankees play Neil Diamond's 'Sweet Caroline,' a staple at Fenway. http://www.nydailynews.com/sports/baseball/yankees-honor-boston-play-sweet-caroline-wake-bombings-article1.1318805. Accessed 2014-04-10

23. Dudek M (2013) Chicagoans run to show solidarity with Boston Marathon victims - Chicago Sun-Times. http://www.suntimes.com/news/metro/19530547-418/chicagoans-run-to-show-solidarity-with-boston-marathonvictims.html. Accessed 2014-04-10

24. Davies C (2013) London reclaims marathon spirit with Boston tribute. http://www.theguardian.com/sport/2013/apr/21/london-marathon-boston-bombings-tribute. Accessed 2014-04-10

25. Palen L, Vieweg S (2008) The emergence of online widescale interaction in unexpected events: assistance, alliance and retreat. In: CSCW2008, pp 117-126

26. Castells M (2011) The rise of the network society: the information age: economy, society, and culture, vol 1. Wiley, New York

27. Beck U, Levy D (2013) Cosmopolitanized nations: re-imagining collectivity in world risk society. Theory Cult Soc 30(2):3-31. doi:10.1177/0263276412457223

28. Rainie H, Wellman B (2012) Networked: the new social operating system

29. Tajfel H, Turner JC (1979) An integrative theory of intergroup conflict. In: The social psychology of intergroup relations, pp 33-47

30. Turner RH (1967) Types of solidarity in the reconstituting of groups. Pac Sociol Rev 10(2):60-68. doi:10.2307/1388423

31. Renn O, Burns WJ, Kasperson JX, Kasperson RE, Slovic P (1992) The social amplification of risk: theoretical foundations and empirical applications. J Soc Issues 48(4):137-160.

32. Lee JE, Lemyre L, Krewski D (2010) A multi-method, multi-hazard approach to explore the uniqueness of terrorism risk perceptions and worry. J Appl Soc Psychol 40(1):241-272.

33. Gierlach E, Belsher BE, Beutler LE (2010) Cross-cultural differences in risk perceptions of disasters: cross-cultural differences in risk perceptions of disasters. Risk Anal 30(10):1539-1549. doi:10.1111/j.1539-6924.2010.01451x

34. Marshall RD, Bryant RA, Amsel L, Suh EJ, Cook JM, Neria Y (2007) The psychology of ongoing threat: relative risk appraisal, the September 11 attacks, and terrorism-related fears. Am Psychol 62(4):304-316. doi:10.1037/0003-066X.62.4.304

35. Arquilla J, Ronfeldt D (2001) Networks and netwars: the future of terror, crime, and militancy. Rand Corporation

36. Zeitzoff T (2014) Anger, exposure to violence, and intragroup conflict: a 'lab in the field' experiment in southern Israel: anger, exposure to violence, and intragroup conflict. Polit Psychol 35(3):309-335. doi:10.1111/pops.12065

37. Fritz CE, Williams HB (1957) The human being in disasters: a research perspective. Ann Am Acad Polit Soc Sci 309:42-51

38. Beyerlein K, Sikkink D (2008) Sorrow and solidarity: why Americans volunteered for 9/11 relief efforts

39. Turkel G (2002) Sudden solidarity and the rush to normalization: toward an alternative approach. Sociol Focus 35(1):73-79

40. Starbird K, Palen L (2010) Pass it on?: Retweeting in mass emergency. In: 7th annual ISCRAM conference. International Community on Information Systems for Crisis Response and Management, Seattle

41. Anagondahalli D, Turner MM (2012) Predicting psychological ripple effects: the role of cultural identity, in-group/out-group identification, and attributions of blame in crisis communication: predicting psychological ripple effects. Risk Anal 32(4):695-712. doi:10.1111/j.1539-6924.2011.01727.x

42. Balzarotti S, Ciceri MR (2014) News reports of catastrophes and viewers' fear: threat appraisal of positively versus negatively framed events. Media Psychol 17:357-377. doi:10.1080/15213269.2013.826588

43. Bracha HS, Burkle FM (2006) Utility of fear severity and individual resilience scoring as a surge capacity, triage management tool during large-scale, bio-event disasters. Prehosp Disaster Med 21:290-296.

44. Weinstein ND, Lyon JE, Rothman AJ, Cuite CL (2000) Changes in perceived vulnerability following natural disaster. J Soc Clin Psychol 19(3):372-395

45. Benzion U, Shahrabani S, Shavit T, Weiss R (2012) Emotions and economic expectations: a field study. Econ Bull 32(2):1455-1460

46. Baumann J, DeSteno D (2010) Emotion guided threat detection: expecting guns where there are none. J Pers Soc Psychol 99(4):595.

47. Maguen S, Papa A, Litz B (2008) Coping with the threat of terrorism: a review. Anxiety Stress Coping 21(1):15-35 doi:10.1080/10615800701652777

48. Drury J, Cocking C, Reicher S (2009) The nature of collective resilience: survivor reactions to the 2005 London bombings. Int J Mass Emerg Disasters 27(1):66-95

49. Shavit T, Shahrabani S, Benzion U, Rosenboim M (2013) The effect of a forest fire disaster on emotions and perceptions of risk: a field study after the Carmel fire. J Environ Psychol 36:129-135. doi:10.1016/j.jenvp.2013.07.018

50. Bakshy E, Rosenn I, Marlow C, Adamic L (2012) The role of social networks in information diffusion. In: Proceedings of the 21st international conference on World Wide Web, pp 519-528

51. Miller A, Leshner G (2007) How viewers process live, breaking, and emotional television news. Media Psychol 10:23-40

52. Vasterman PL, Ruigrok N (2013) Pandemic alarm in the Dutch media: media coverage of the 2009 influenza A (H1N1) pandemic and the role of the expert sources. Eur J Commun 28(4):436-453. doi:10.1177/0267323113486235

53. Palen L, Vieweg S, Liu SB, Hughes AL (2009) Crisis in a networked world features of computer-mediated communication in the April 16, 2007, Virginia Tech Event. Soc Sci Comput Rev 27(4):467-480.

54. Hughes AL, Palen L (2009) Twitter adoption and use in mass convergence and emergency events. Int J Emerg Manag 6(3):248-260

55. Sutton JN (2010) Twittering Tennessee: distributed networks and collaboration following a technological disaster. In: ISCRAM

56. Qu Y, Wu PF, Wang X (2009) Online community response to major disaster: a study of Tianya forum in the 2008 Sichuan earthquake. In: 42nd Hawaii international conference on System sciences, 2009, HICSS'09, pp 1-11

57. Zhou Z, Bandari R, Kong J, Qian H, Roychowdhury V (2010) Information resonance on Twitter: watching Iran. In: Proceedings of the first workshop on social media analytics, pp 123-131 
58. Liu SB, Palen L, Sutton J, Hughes AL, Vieweg S (2008) In search of the bigger picture: the emergent role of on-line photo sharing in times of disaster. In: ISCRAM2008

59. Karlsson MB (2010) Participatory journalism and crisis communications: a Swedish case study of swine flu coverage. Observatorio $\left(\mathrm{OBS}^{*}\right)$ 4(1):201-220

60. Mark G, Semaan B (2008) Resilience in collaboration: technology as a resource for new patterns of action. In: Proceedings of the 2008 ACM conference on computer supported cooperative work, pp 137-146

61. Oh O, Agrawal M, Rao HR (2011) Information control and terrorism: tracking the Mumbai terrorist attack through twitter. Inf Syst Front 13(1):33-43. doi:10.1007/s10796-010-9275-8

62. Vieweg S, Hughes AL, Starbird K, Palen L (2010) Microblogging during two natural hazards events: what twitter may contribute to situational awareness. In: Proceedings of the SIGCHI conference on human factors in computing systems, pp 1079-1088

63. Yin J, Lampert A, Cameron M, Robinson B, Power R (2012) Using social media to enhance emergency situation awareness. IEEE Intell Syst 27(6):52-59. doi:10.1109/MIS.2012.6

64. Palen L, Anderson KM, Mark G, Martin J, Sicker D, Palmer M, Grunwald D (2010) A vision for technology-mediated support for public participation \& assistance in mass emergencies \& disasters. In: Proceedings of the 2010 ACM-BCS visions of computer science conference, $\mathrm{p} 8$

65. Mendoza M, Poblete B, Castillo C (2010) Twitter under crisis: can we trust what we RT?. In: Proceedings of the first workshop on social media analytics, pp 71-79

66. Aramaki E, Maskawa S, Morita M (2011) Twitter catches the flu: detecting influenza epidemics using twitter. In: Proceedings of the conference on empirical methods in natural language processing, pp 1568-1576

67. Chew C, Eysenbach G (2010) Pandemics in the age of Twitter: content analysis of Tweets during the $2009 \mathrm{H} 1 \mathrm{~N}$ outbreak. PLOS ONE 5(11):e14118.

68. de Quincey E, Kostkova P (2010) Early warning and outbreak detection using social networking websites: the potential of twitter. In: Electronic healthcare. Springer, Berlin, pp 21-24

69. Sakaki T, Okazaki M, Matsuo Y (2010) Earthquake shakes Twitter users: real-time event detection by social sensors. In: Proceedings of the 19th international conference on World wide web, pp 851-860

70. Guy M, Earle P, Ostrum C, Gruchalla K, Horvath S (2010) Integration and dissemination of citizen reported and seismically derived earthquake information via social network technologies, pp 42-53

71. Earle PS, Bowden DC, Guy M (2012) Twitter earthquake detection: earthquake monitoring in a social world. Ann Geophys 54(6):708-715

72. Caragea C, McNeese N, Jaiswal A, Traylor G, Kim H-W, Mitra P, Wu D, Tapia AH, Giles L, Jansen BJ (2011) Classifying text messages for the Haiti earthquake. In: ISCRAM2011

73. Li J, Rao HR (2010) Twitter as a rapid response news service: an exploration in the context of the 2008 China earthquake. Electron J Inf Syst Dev Ctries 42:1-22.

74. Ratkiewicz J, Conover M, Meiss M, Gonçalves B, Patil S, Flammini A, Menczer F (2011) Truthy: mapping the spread of astroturf in microblog streams. In: Proceedings of the 20th international conference companion on World wide web, pp 249-252

75. Starbird K, Maddock J, Orand M, Achterman P, Mason RM (2014) Rumors, false flags, and digital vigilantes: misinformation on twitter after the 2013 Boston marathon bombing. In: iConference 2014 proceedings, iSchools. doi:10.9776/14308

76. Gupta A, Lamba H, Kumaraguru P, Joshi A (2013) Faking Sandy: characterizing and identifying fake images on Twitter during hurricane Sandy. In: Proceedings of the 22nd international conference on World Wide Web companion, pp $729-736$

77. Caragea C, Squicciarini A, Stehle S, Neppalli K, Tapia A (2014) Mapping moods: geo-mapped sentiment analysis during hurricane Sandy. In: Proceedings of the 11th international ISCRAM conference, University Park, PA

78. de Albornoz JC, Plaza L, Gervás P (2012) SentiSense: an easily scalable concept-based affective lexicon for sentiment analysis. In: LREC, pp 3562-3567

79. Gonçalves P, Araújo M, Benevenuto F, Cha M (2013) Comparing and combining sentiment analysis methods. In: Proceedings of the first ACM conference on online social networks, pp 27-38

80. Socher R, Perelygin A, Wu JY, Chuang J, Manning CD, Ng AY, Potts C (2013) Recursive deep models for semantic compositionality over a sentiment treebank. In: Proceedings of the conference on empirical methods in natural language processing (EMNLP), pp 1631-1642

81. Mostak T, Lewis B (2012) TweetMap: a sample big geodata exploration tool powered by MapD and WorldMap. http://worldmap.harvard.edu/tweetmap/. Accessed 2013-04-16

82. United Nations Population Division (2009) United Nations Population Division | Department of Economic and Social Affairs. http://www.un.org/en/development/desa/population/publications/urbanization/urban-rural.shtml. Accessed 2014-06-16

83. Geography, US Census Bureau 2010 Census urban and rural classification and urban area criteria. 2010 Census urban and rural, classification, criteria, lists, urban population, urban cluster. http://www.census.gov/geo/reference/ua/urban-rural-2010.html. Accessed 2014-06-16

84. Box GE, Cox DR (1964) An analysis of transformations. J R Stat Soc, Ser B, Methodol 26:211-252.

85. Lin Y-R, Margolin D, Keegan B, Baronchelli A, Lazer D (2013) \#Bigbirds never die: understanding social dynamics of emergent hashtag. In: Proceedings of ICWSM, AAAI

86. Glasgow K, Fink C (2013) From push brooms to prayer books: social media and social networks during the London riots Fort Worth, TX

87. Batson CD, Ahmad NY (2009) Using empathy to improve intergroup attitudes and relations. Soc Issues Policy Rev 3(1):141-177.

88. Zimmer B (2013) 'Boston Strong', the phrase that rallied a city. Boston Globe

89. Nurmi J, Rasanen P, Oksanen A (2012) The norm of solidarity: experiencing negative aspects of community life after a school shooting tragedy. J Soc Work 12(3):300-319. doi:10.1177/1468017310386426

90. McCullagh P, Nelder J (1989) Generalized linear models. Chapman and Hall/CRC, Boca Raton 
doi:10.1140/epjds/s13688-014-0031-z

Cite this article as: Lin and Margolin: The ripple of fear, sympathy and solidarity during the Boston bombings. EPJ Data Science 2014 3:31.

Submit your manuscript to a SpringerOpen ${ }^{\circ}$ journal and benefit from:

- Convenient online submission

- Rigorous peer review

- Immediate publication on acceptance

- Open access: articles freely available online

- High visibility within the field

- Retaining the copyright to your article

Submit your next manuscript at $\gg$ springeropen.com 